\title{
Save a Child's Heart: A Unique Global Health Model
}

\author{
Shirley Shuster ${ }^{1}$, Zane Brickman², Dalia Karol ${ }^{1}$, Itai Malkin ${ }^{1}$
}

All authors contributed equally

${ }^{1}$ Faculty of Medicine, University of Ottawa

${ }^{2}$ Faculty of Medicine, University of Toronto

ABSTRACT

Save a Child's Heart (SACH) is a UN-sponsored Israeli non-profit organization that provides free, life-saving cardiac treatment to children from developing countries who would otherwise be unable to receive sufficient medical care in their home country. SACH utilizes a unique model of care involving several areas of focus including a tertiary care centre in Israel, international screening missions, training local healthcare professionals (HCPs), establishing local care facilities in partner countries, and engaging local and international volunteers. Through these efforts, SACH has been successful in providing cardiac care to 4599 children, training 116 $\mathrm{HCPs}$, and establishing four independent surgical centres internationally. This model has proven its efficacy and can be applied to other tertiary surgical endeavors.

\section{RÉSUMÉ}

Sauver le coeur d'un enfant (SACH) est un organisme Israélien à but non lucratif parrainé par l'ONU qui offre des soins cardiaques gratuits et vitaux aux enfants des pays en développement qui seraient autrement incapables de recevoir des soins médicaux suffisants dans leur pays d'origine. SACH utilise un modèle unique de soins impliquant plusieurs domaines, dont un centre de soins tertiaires en Israël, des missions de dépistage internationales, la formation de professionnels de santé locaux, la mise en place de centres de soins locaux dans les pays partenaires et l'engagement de volontaires locaux et internationaux. Grâce à ces efforts, SACH a réussi à fournir des soins cardiaques à 4599 enfants, à former 116 HCPs et à établir quatre centres chirurgicaux indépendants à l'échelle internationale. Ce modèle a prouvé son efficacité et peut être appliqué à d'autres efforts chirurgicaux tertiaires.

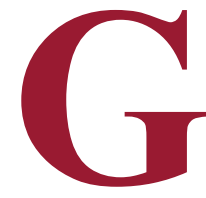

lobal health initiatives are essential to tackling global inequity. This article will explore the ways in which SACH, a unique global health initiative, has emphasized sustainability and can thus be used as a global health model. SACH is a UN-sponsored Israeli nonprofit organization that provides free, life-saving cardiac treatment to children from developing countries who would be otherwise unable to receive sufficient medical care in their home country (1). The majority of children who present to SACH carry the diagnosis of Rheumatic Heart Disease (RHD) or Congenital Heart Disease (CHD), both of which bear a poor prognosis without treatment (1). Notably, more than 15 million people are diagnosed with RHD worldwide. The prevalence of RHD is highest in Sub-Saharan Africa (1 to 14 per 1000) and the 180-day mortality rate is observed to be as high as $17.8 \%$ (2). The incidence of CHD has been estimated at $\sim 1 \%$ of live births (2). It is known to be the most common congenital malformation and is the leading cause of mortality as a result of congenital defects. A systematic review identified variations in mortality rates of $\mathrm{CHD}$ worldwide which differed based on the availability of surgical and medical care (3). Such variations ranged from $3-7 \%$ to $20 \%$ in developed and developing countries, respectively (3). The $20 \%$ mortality rate in developing countries was also thought to be an under-reported value. This marked variation in mortality from CHD has been attributed to advances in developed countries in prenatal diagnosis, access to tertiary care centres, and medical and surgical treatment options for CHD. The lack of sustainable strategies for screening and prevention programs, financial resources, trained healthcare providers, and access to tertiary care centres for medical or surgical treatment in developing countries have also been contributing factors. The burden of CHD in developing countries and the need for improvement in care was demonstrated by the establishment of the World Society for Pediatric and Congenital Heart Surgery (WSPCHS) in 2006. The vision of WSPCHS is as follows: "that every child born anywhere in the world with a congenital heart defect should have access to appropriate medical and surgical care" (4). 
Individual patients receive short-term solutions from many global health initiatives, whereas long-term sustainable solutions are neglected. Attempts to overcome barriers to cardiac surgery in developing countries have included the transfer of children to countries abroad to receive care, as well as medical missions of surgical teams. Despite the short-term successes of such attempts, many global health initiatives do not achieve long-term solutions (2). Innovative, unique solutions are needed in developing countries as the current sporadic provision of cardiac care has had minimal impact; the optimal strategy in terms of sustainability involves local training and education (5). This is further supported by the demonstrated discrepancies between developed and developing countries in terms of disease burden and health workforce: Africa makes up over $24 \%$ of global disease but only $3 \%$ of global health workforce, in comparison to the Americas which make up 37\% of the global health workforce, but only $10 \%$ of global disease (6).

SACH follows a unique global health model that demonstrates sustainability through its emphasis on long-term solutions. This is achieved by training healthcare professionals (HCPs) from developing countries as well as undergraduate medical students, and by establishing independent surgical centres in its partner countries (7). These initiatives help fill in the missing gaps for long-term solutions in addition to highlighting the importance of trainees in the process. This model is based on the following four pillars: 1) use of a tertiary care centre in Israel; 2) international screening missions to developing countries in collaboration with other non-governmental organizations (NGOs); 3) training local HCPs at the Israeli tertiary centre and establishing local care facilities in partner countries; 4 ) local and international volunteers that provide service in Israel, learn humanitarian work, and act as local ambassadors in their home countries (1). The efforts and impact of the sustainability of SACH's global health model can be quantified in a number of ways, including an evaluation of the number of HCPs trained, medical missions, independent surgical centres, and volunteers. SACH's emphasis on sustainability has resulted in $116 \mathrm{HCPs}$ from 17 different countries being trained between 1996 and 2016 (7). Each HCP was trained in one of 8 different fields (Figure 1). The most common fields of training have been anesthesiology $(n=32)$, nursing $(n=26)$, surgery $(n=21)$, cardiology $(n=17)$, and intensive care $(n=13)(7)$. Fourteen of the countries from which trained HCPs came from are part of the 53 countries in which SACH has provided cardiac care. SACH has also sent 73 medical missions to 13 countries as of 2017 (Figure 2). SACH has estab- lished independent surgical centres in four of these countries: Romania, Moldova, Tanzania, and China. Currently, the organization is working to establish centres in Ethiopia and Ramallah (West Bank) (7). Furthermore, SACH has attracted 789 volunteers and medical interns between 2012 and 2017 (7), over half of which have been from Canada and the United States, while the remainder have been from 22 other countries (Figure 3 ).

Ultimately, these efforts have resulted in SACH providing medical care for 4599 children with heart conditions who were treated between 1996 and 2017 (7). Of note, 2159 (47\%) of these children are Palestinians from the West Bank and Gaza. The remaining 2440 (53\%) are from the 53 other countries served by SACH (Figure 4). A visualization of SACH's international impact is presented through a map in Figure $\mathbf{5}$ which highlights the home countries of SACH patients, HCPs, and independent surgical centres.

The takeaway from SACH's mission is "we can and we should." This statement is the title of the first article concerning $\mathrm{SACH}$ written by the founder of $\mathrm{SACH}$, Dr. Ami Cohen, and his colleagues (8).

"We Can." SACH has a comprehensive and unique model, as demonstrated above, and has the ability to create long-term improvement in cardiac care in low- and middle-income countries. SACH does this by training local health care professionals and undergraduate medical students, as well as establishing independent surgical centres in partner countries. Despite the importance of transferring patients to receive healthcare abroad and the need for healthcare teams to visit developing countries, these are ultimately not long-term solutions to global health issues. SACH has demonstrated through its unique four pillar model that establishing a long-term solution for global health issues is attainable.

"We Should." Every patient has the right to be treated regardless of their country of origin, race, sex, religion, socioeconomic background, and political beliefs. SACH continues to work toward making a positive and long-lasting impact on children in developing countries. This includes treating Palestinian children from the West Bank and Gaza who make up close to 50\% of SACH children.

The SACH model of care is not only applicable to cardiac surgery and cardiac medical interventions; it is a model that has 


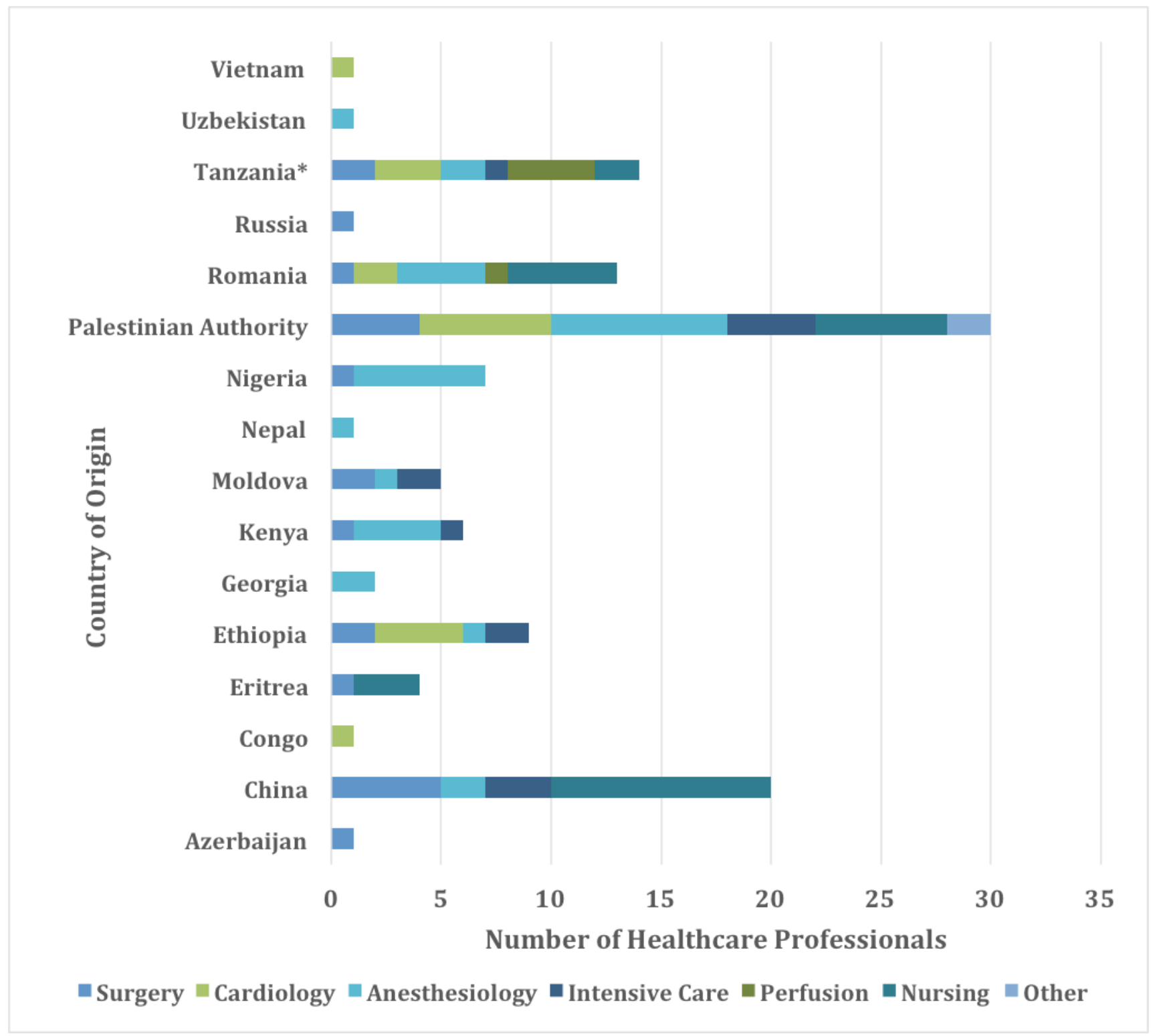

Figure 1. Number of healthcare professionals that have been trained by SACH stratified by medical discipline/specialty (1996-2016) ( $n=116)$. HCPs are grouped by country of origin. The 2 HCPs from the 'Other' category from the Palestinian Authority include 1 in Radiology and 1 in Fetal Ultrasound. *Healthcare professionals from Tanzania includes those from Zanzibar (7). 


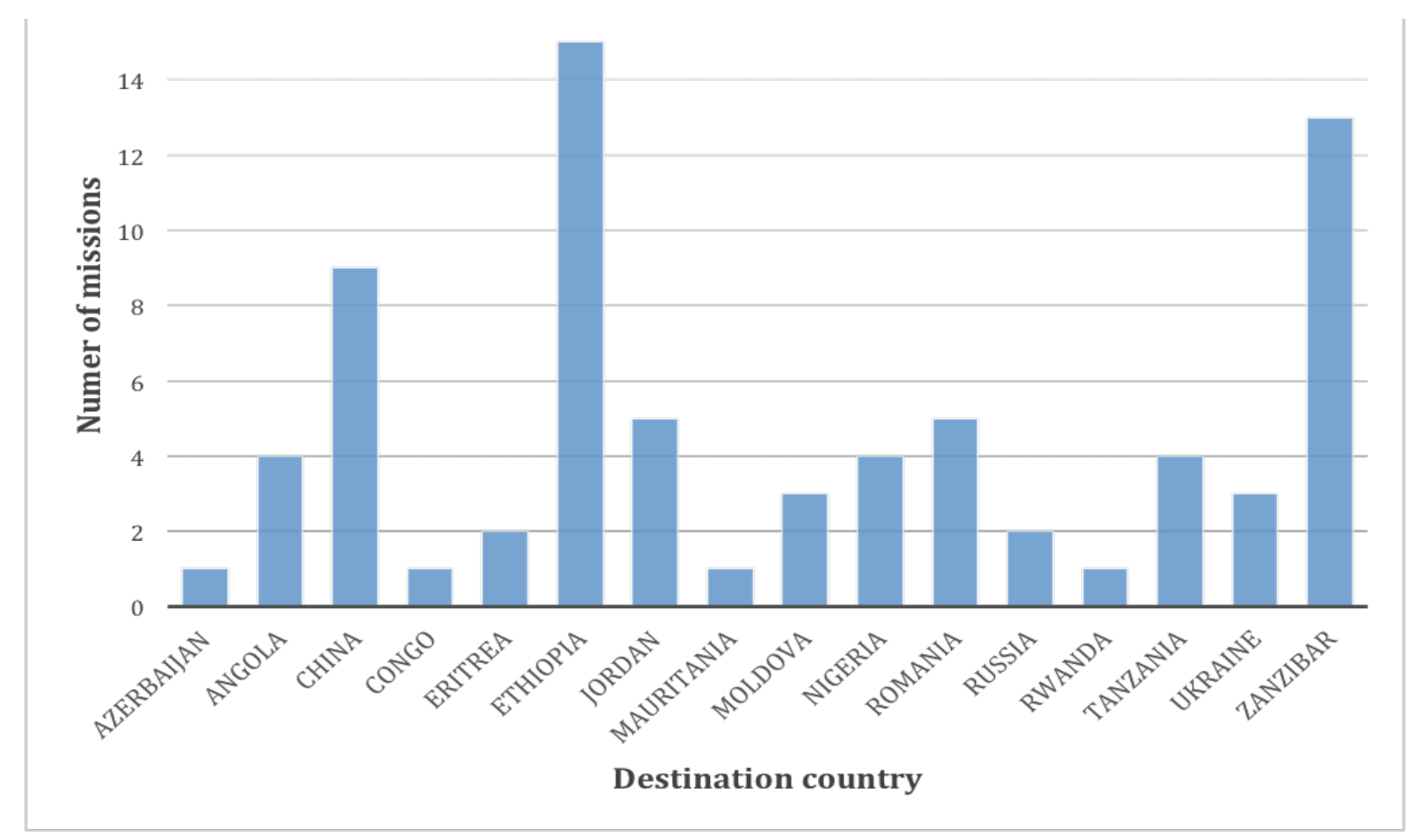

Figure 2. Destination countries and the associated number of missions that SACH has undertaken between 1996$2016(n=73)$.

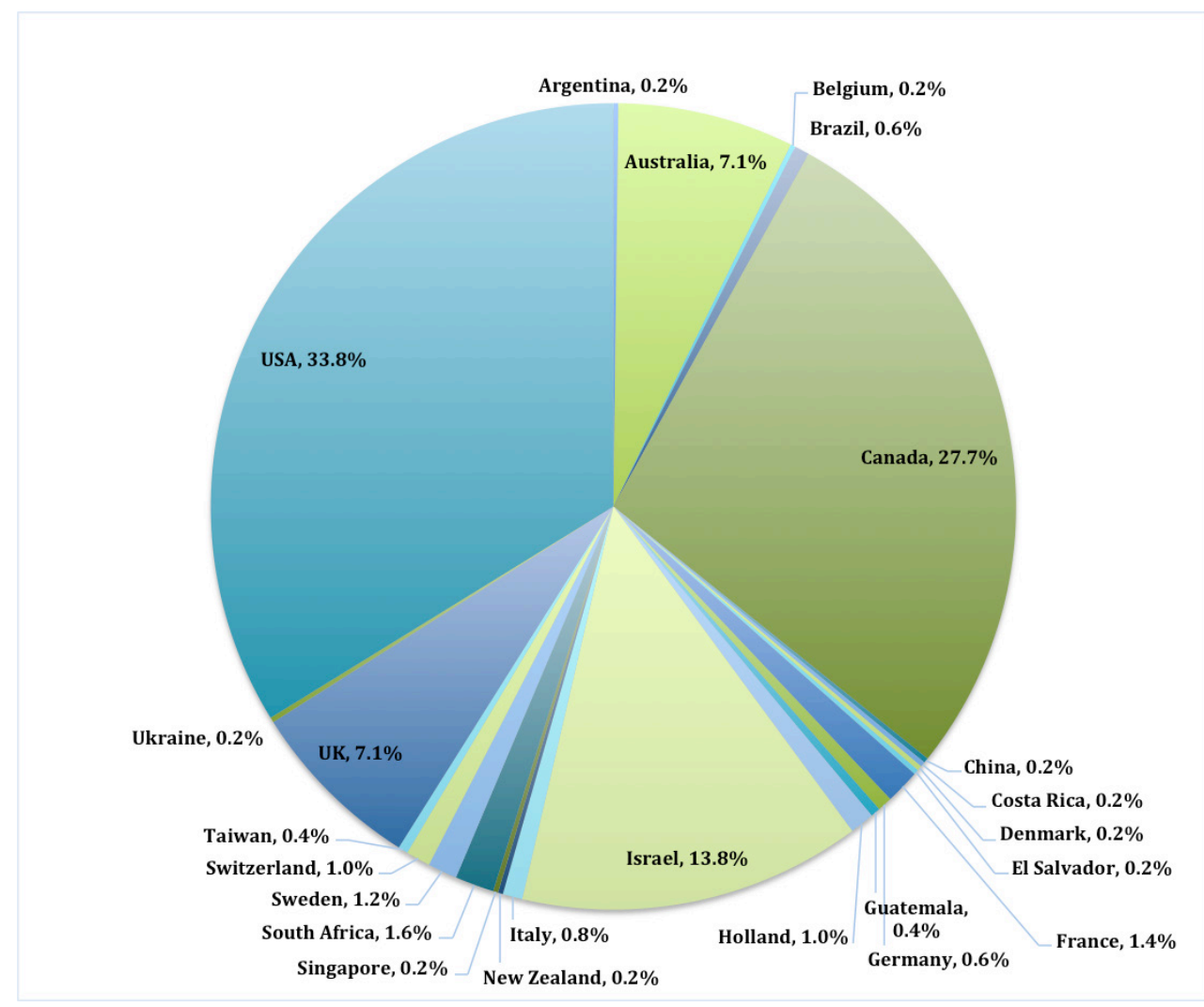

Figure 3. International volunteers with SACH (2012-2017). Proportion of individuals that have volunteered with SACH based on country $(n=789)$. 


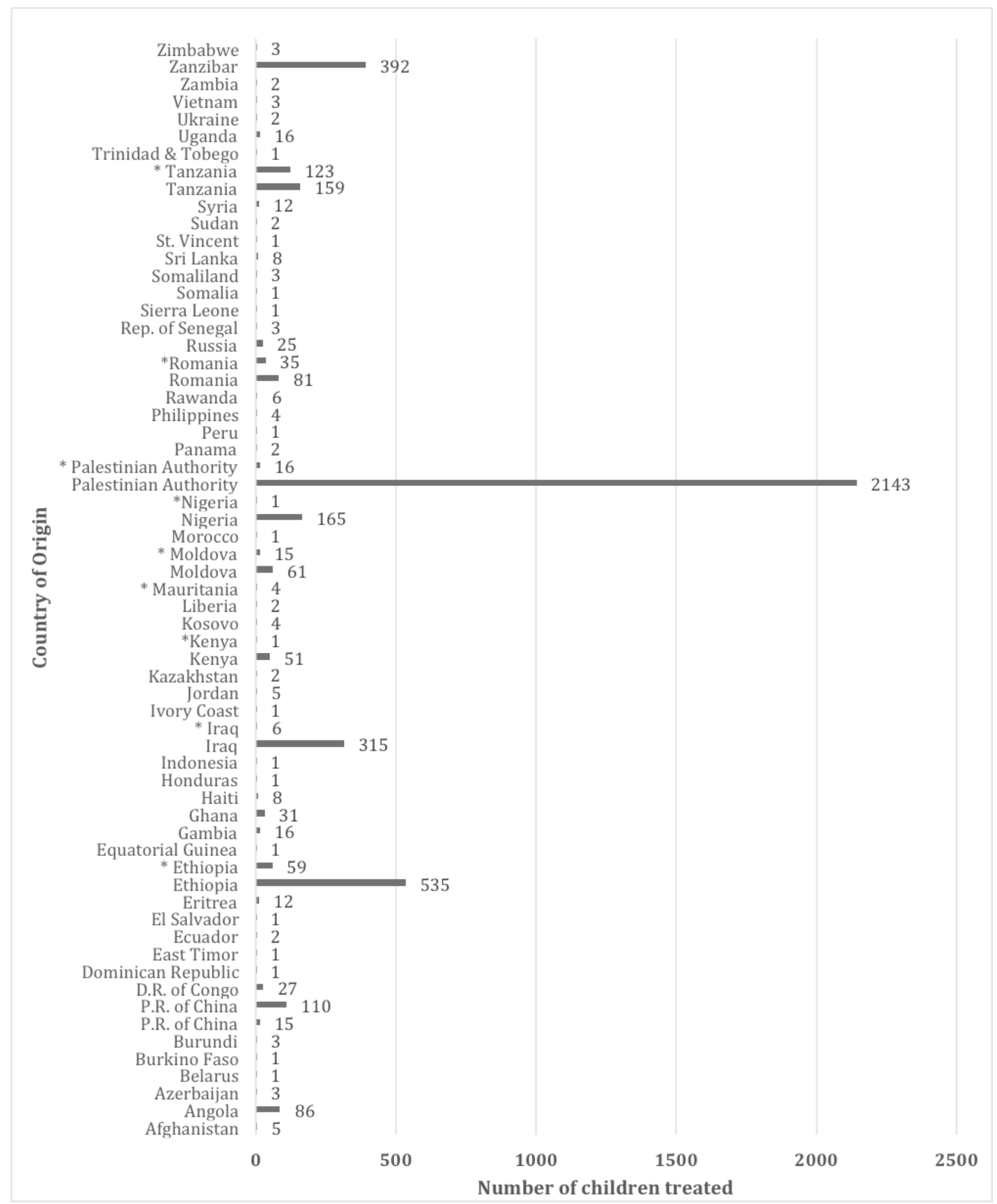

Figure 4. Children treated by SACH (1996-2017). Number and origin of children treated by SACH ( $n=4599) .{ }^{*}$ Implies that children were treated in home country. 


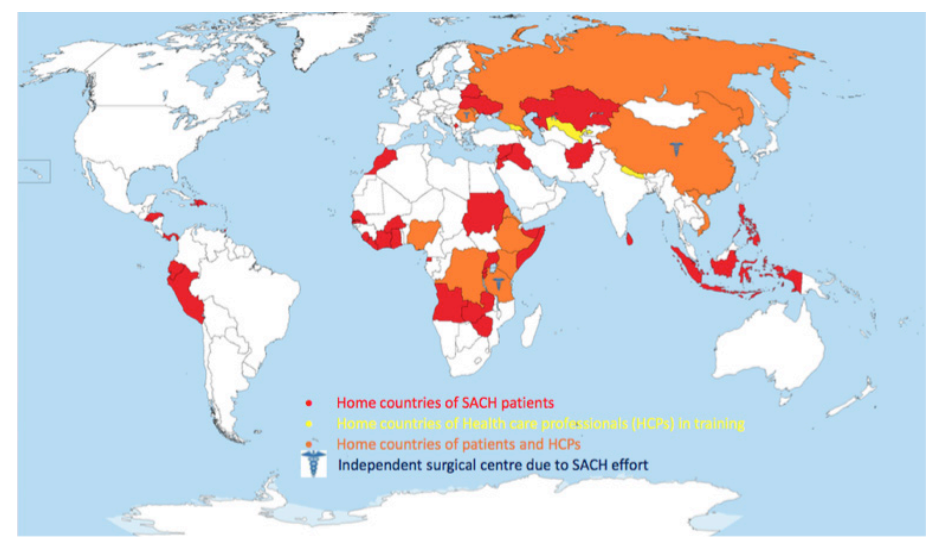

Figure 5. Visualization of SACH's international impact.

proven its efficacy and can be applied to other tertiary surgical endeavors. For instance, surgical interventions can be applied to craniofacial reconstruction, neurosurgery, complex spine surgeries, and other conditions that have a high level of burden in developing countries (1). Such endeavors can adopt the unique SACH global health model: a tertiary care site with locally-trained doctors who are skilled enough to simultaneously deliver local care and training (1). Perhaps this will allow us to one day see the world's heart beat as one.

\section{REFERENCES}

1. Karol D, Shuster S, Malkin I. Saving children's hearts: A global challenge [Internet]. Ottawa (ON): University of Ottawa Global Health Conference; 2017 Sep 30 [cited 2018 Mar 30]. Available from: http://www.aghnconference. com/research-symposium.

2. Zühlke $L$, Mirabel M, Marijon E. Congenital heart diseases and rheumatic heart disease in Africa: recent advances and current priorities. Heart. 2013;99:1554-1561.

3. Bernier PL, Stefanescu A, Samoukovic G, Tchervenkov Cl. The challenge of congenital heart disease worldwide: epidemiologic and demographic facts. Semin Thorac Cardiovasc Surg Surg Pediatr Card Surg Annu. 2010;13(1):2634.

4. World Society for Pediatric and Congenital Heart Surgery [Internet]. ND. Available from: https://www.wspchs.org/.

5. Tchervenkov $\mathrm{Cl}$, Jacobs JP, Bernier PL, et al. The improvement of care of pediatric and congenital cardiac disease across the world: a challenge for the World Society for Pediatric and Congenital Heart Surgery. Cardiol Young. 2008;18(2):63-69.

6. Anyangwe SCE, Mtonga C. Inequities in the global health workforce: the greatest impediment to health in Sub-Saharan Africa. Int J Environ. 2007;4(2):93-100.

7. Save a Child's Heart [Internet]. ND [cited 2018 Mar 30]. Available from: https://www.saveachildsheart.com/saving-lives/activities-reports.html.

8. Cohen A, Tamir A, Houri S, et al. Save a Child's Heart: we can and we should. Ann Thorac Surg. 2001;71:462-468.

9. Sasson L, Tamir A, Houri S, et. al. Mending hearts and building bridges: the Save A Child's Heart foundation. Journal of Public Health Management and Practice. 2016;22(1):89-98. 